\title{
Overexpression of Musashi-1 protein is associated with progression and poor prognosis of gastric cancer
}

\author{
ZHANGXUAN SHOU $^{1}$, XUE JIN ${ }^{1}$, XUJUN HE ${ }^{2}$, ZHONGSHENG ZHAO ${ }^{3}$, \\ YUAN CHEN $^{3}$, MEIHUA YE ${ }^{3}$ and JIONG YAO ${ }^{4}$
}

\author{
${ }^{1}$ Department of Pharmaceutical Sciences, Zhejiang Provincial People's Hospital, People's Hospital \\ of Hangzhou Medical College; ${ }^{2}$ Key Laboratory of Gastroenterology of Zhejiang; ${ }^{3}$ Department of Pathology, \\ Zhejiang Provincial People's Hospital, People's Hospital of Hangzhou Medical College; \\ ${ }^{4}$ Department of Medical Records and Statistics, Zhejiang Provincial People's Hospital, People's Hospital \\ of Hangzhou Medical College, Hangzhou, Zhejiang 310014, P.R. China
}

Received August 13, 2015; Accepted January 12, 2017

DOI: $10.3892 / \mathrm{ol} .2017 .5879$

\begin{abstract}
Musashi-1, an evolutionally conserved RNA-binding protein, has been implicated in the promotion of pathological stem cell proliferation, including tumorigenesis. The objective of the present study was to evaluate the expression of Musashi-1 protein and its implications in the progression and prognosis of gastric cancer. The expression level of Musashi-1 protein in gastric cancer was determined by western blotting and immunohistochemistry, and compared with the clinicopathological parameters. The present study revealed that the expression level of Musashi-1 protein in gastric cancer was significantly upregulated and correlated with the tumor size, tumor-node-metastasis (TNM) stage, Lauren classification, depth of invasion, vessel invasion, lymph node metastasis and distant metastasis. The mean survival time for patients with low expression levels of Musashi-1 was significantly longer compared with patients with high expression levels of Musashi-1. For each TNM stage, the mean survival time for patients with a low Musashi-1 expression levels was also significantly longer compared with patients with a high Musashi-1 expression level. Notably, TNM stage II patients with a low Musashi-1 expression level demonstrated a longer mean survival time compared with TNM stage I patients with high Musashi-1 expression level (56.8 vs. 42.3 months; $\mathrm{P}=0.001$ ), and TNM stage III patients with low Musashi-1 expression level exhibited a longer mean survival time compared with TNM stage II patients with a high Musashi-1 expression level (44.0 vs. 33.8 months; $\mathrm{P}=0.034$ ). Multivariate Cox's regression
\end{abstract}

Correspondence to: Professor Zhongsheng Zhao, Department of Pathology, Zhejiang Provincial People's Hospital, People's Hospital of Hangzhou Medical College, 158 Shangtang Road, Hangzhou, Zhejiang 310014, P.R. China

E-mail: zhaozhongsheng1950@163.com

Key words: musashi-1, gastric cancer, tissue microarray, immunohistochemistry, western blotting, prognosis test demonstrated that Musashi-1 protein expression level was an independent prognostic indicator for the survival rate of the patients with gastric cancer. The results of the present study highlighted an important role for Musashi-1 protein in the progression of gastric cancer. The detection of the Musashi-1 protein expression level alone or in combination with TNM staging may aid the prediction of the prognosis of patients with gastric cancer.

\section{Introduction}

Gastric cancer is the fifth most common malignancy and the third leading cause of cancer-associated mortality (1), and still poses a considerable global health burden, despite a substantial decrease in the incidence of cancer for the majority of the world (2). In China, gastric cancer is the third most frequently occurring type of cancer and cause of cancer-associated mortality (3). Approximately 405,000 novel cases are diagnosed every year in China, accounting for $42.5 \%$ of the worldwide total (4). Gastric cancer is often asymptomatic or induces only nonspecific symptoms in its early stages (5). Consequently, it is often diagnosed at the advanced stages and is associated with a poor prognosis (5). According to a statistical study, $\sim 70 \%$ of patients with gastric cancer have lymph node metastasis at the time of diagnosis, leading to a median overall survival time of 16.7 months (6). Complete resection of the primary tumor with D2 lymphadenectomy is the only method of curing the disease in the early stages (6). Early detection as well as the availability and reliability of appropriate biomarkers may contribute towards the effective treatment of gastric cancer (7).

At present, the molecular mechanisms underlying gastric cancer have not been well elucidated, owing to the currently limited knowledge of germline susceptibility traits for risk and somatic drivers of progression (8). The presence of cancer stem cells has been demonstrated to be associated with the initiation, metastasis, chemoresistance and rapid recurrence of various types of tumor (9). Musashi-1, a highly conserved RNA-binding protein, has been characterized as a putative stem or progenitor cell marker (10). It serves important roles in cell 
fate decision, including the maintenance of the stem cell state, differentiation and tumorigenesis (10). Musashi-1-mediated translational control has been implicated to promote pathological and physiological stem cell proliferation (11). Loss of Musashi-1 function disrupts the balance between germ-line stem cell differentiation and renewal, leading to premature germ-line stem cell differentiation (12). The Musashi-1 signaling pathway has previously been reported to be upregulated in numerous types of tumor, including glioma (13), esophageal adenocarcinoma (14), colorectal cancer $(15,16)$, gallbladder adenocarcinoma (17), endometrial carcinoma (18) and small intestinal adenocarcinoma (19). Furthermore, Musashi-1 has been identified as a biomarker associated with cancer progression and poor prognosis in patients with breast cancer (20), ovarian adenocarcinoma (21) and oral squamous cell carcinoma (22).

Musashi-1 is a candidate stem cell marker in the human stomach and mouse intestine, and a marker for progenitor cells in the human stomach (23). Musashi-1-positive cells may serve a key role in the early events occurring during carcinogenesis, and may be involved in the progression of gastric cancer (24). It was previously revealed that the expression levels of Musashi-1 were significantly elevated in gastric cancer and precancerous lesions, including intestinal metaplasia and dysplasia $(24,25)$. By contrast, an immunohistochemistry study demonstrated that Musashi-1 expression in the gastric glands with intestinal metaplasia was lower compared with that in glands without intestinal metaplasia (26). Currently, the expression pattern of Musashi-1 protein and its impact on the progression and prognosis of gastric cancer has not yet been elucidated.

With an aim to evaluate the clinicopathological implications of Musashi-1 in the progression and prognosis of gastric cancer, the present study detected the expression of Musashi-1 protein in gastric cancer tissues by western blotting and immunohistochemistry, and compared Musashi-1 expression levels with the clinicopathological parameters and survival rates of 436 patients with gastric cancer. The present study revealed that Musashi-1 protein was significantly upregulated in gastric cancer tissues and was associated with the progression and poor prognosis of gastric cancer.

\section{Materials and methods}

Patients and tissue specimens. The present study was approved by the Institutional Review Board of Zhejiang Provincial People's Hospital (Hangzhou, China). Written informed consent was obtained from all patients prior to enrollment in the present study. All specimens were anonymously handled in accordance with the Declaration of Helsinki and legal standards.

For western blotting, 36 patients who underwent gastrectomy for gastric cancer at Zhejiang Provincial People's Hospital were recruited between July 2013 and February 2014. All cases were diagnosed clinically at the Department of Gastrointestinal Surgery and histopathologically at the Department of Pathology (Zhejiang Provincial People's Hospital). These patients consisted of 19 males and 17 females, with a mean age of 66.7 years (range, 47-78 years) at the time of surgery. According to the Lauren classification (27), there were 18 diffuse-type and 20 intestinal-type gastric cancer tissues. Following gastric resection, fresh specimens of cancerous and matched non-cancerous tissues (adjacent gastric cancer margins $\geq 5 \mathrm{~cm}$ ) were obtained immediately, dissected, snap-frozen in liquid nitrogen in separate vials and stored at $-80^{\circ} \mathrm{C}$ for further analysis.

For immunohistochemistry, 436 patients who underwent gastrectomy for gastric cancer at Zhejiang Provincial People's Hospital between January 1998 and January 2004 were included in the current study. All cases were diagnosed clinically and histopathologically. The patient cohort consisted of 311 males and 125 females, with a median age of 64 years (range, 30-91 years). All patients had follow-up records for $\geq 5$ years. The follow-up deadline was December 2008. The survival time was determined from the date of surgery to the follow-up deadline or date of mortality. Among the 436 gastric cancer tissues, 55 were from the cardia, 163 from the body and 218 from the gastric antrum. According to the World Health Organization histological classification (28) of gastric carcinoma, 16 cases were identified as papillary, 326 tubular, 29 mucinous and 65 signet-ring cell adenocarcinomas; 13 were highly differentiated, 128 well or moderately differentiated, 293 poorly differentiated and 2 were undifferentiated adenocarcinomas. On the basis of the Lauren classification of gastric cancer, 223 cases were intestinal-type and 213 were diffuse-type. There were 61 cases with distant metastasis and 270 cases with lymph node metastasis. In terms of the 7th edition of the Union for International Cancer Control Tumor-Node-Metastasis (TNM) classification system for gastric cancer (29); 90 cases were categorized as stage I, 104 as stage II, 173 as stage III and 69 as stage IV. A total of 436 gastric cancer tissues and 92 adjacent non-cancerous gastric mucosae were collected following gastrectomy and formalin-fixed and paraffin-embedded (FFPE) for further study. Following surgery, routine chemotherapy was administered to patients with advanced disease, and no radiation treatment was administered to any of the patients.

Evaluation of Musashi-1 protein expression level by western blotting. The Musashi-1 protein expression level was determined by western blotting in extracts of 36 gastric cancer tissues and matched non-cancerous gastric mucosae. Total protein was extracted using the $\mathrm{KC}^{\mathrm{TM}}$ Cell and Tissue Total Protein Extraction kit (KC-415; KangChen Bio-tech Inc., Shanghai, China) containing protease inhibitors $(1 \mathrm{ml} / 250 \mathrm{mg}$ specimen, $1 \mathrm{ml}$ extraction reagent suppleented with $10 \mu \mathrm{l}$ protease inhibitor mixture, $10 \mu \mathrm{l}$ PMSF and $10 \mu 1$ phosphatase mixture). The protein concentration was determined using the $\mathrm{KC}^{\mathrm{TM}}$ bicinchoninic acid assay protein quantification kit (KC-430; KangChen Bio-tech Inc.). A total of $50 \mu \mathrm{g}$ total protein was separated on $10 \%$ polyacrylamide (acrylamide: bisacrylamide, $30: 0.8 \%, w / v)$ SDS gel. The protein was then transferred onto a polyvinylidine fluoride membrane. The membrane was blocked at room temperature for $1 \mathrm{~h}$ with $5 \%$ bovine serum albumin (Amresco, LLC, Solon, OH, USA), followed by incubation at $4^{\circ} \mathrm{C}$ overnight with primary antibody (rabbit monoclonal antibody to human Musashi-1; cat. no. 1877-1; dilution, 1:2,000; Epitomics, Burlingame, CA, USA). Following washing in TBST (Tween-20 0.05\%, v/v; TBS $10 \mathrm{mM}, \mathrm{pH}=7.5$ ) for $5 \mathrm{~min}$ three times, the membrane was incubated with secondary 
antibody (horseradish peroxidase-conjugated anti-rabbit immunoglobulin; catalog no. ab205718; dilution, 1:5,000; Epitomics) at room temperature for $1 \mathrm{~h}$. Following three additional rinses with TBST, immunocomplexes were revealed using the $\mathrm{KC}^{\mathrm{TM}}$ chemiluminescence kit (KC-420, KangChen Bio-tech Inc.). Protein bands were scanned (Tanon 5,200 Multi; Tanon Science and Technology Co., Ltd., Shanghai, China) and quantified using Image J software (version 2.0; National Institutes of Health, Bethesda, MD, USA). Analysis of glyceraldehyde-3-phosphate dehydrogenase (GAPDH) expression levels was carried out as the control for western blotting using mouse monoclonal anti-GAPDH antibody (catalog no. KC-5G4; dilution, 1:10,000; KangChen Bio-tech Inc.).

Tissue microarray (TMA) construction. For diagnostic confirmation and establishing the representative area, $4 \mu \mathrm{m}$ sections were cut from each FFPE tissue specimen and stained with hematoxylin and eosin (H\&E) prior to TMA construction. Subsequently, TMA blocks containing gastric cancer tissues and non-cancerous gastric mucosae were prepared using the method, as described previously (30). Briefly, tissue cylinders $2 \mathrm{~mm}$ in diameter were punched from the targeted area of each donor block and precisely arrayed into a recipient block using a TMA instrument (no. HM315R; GMI, Inc., Ramsey, MN, USA). Each TMA block contained six non-cancerous gastric mucosae as the controls. Consecutive $4 \mu \mathrm{m}$ thick sections were cut from each of the resulting TMA blocks, and one section from each block was H\&E stained for histological verification of the adequacy of the arrayed tumor tissues. Eligible sections were those in which the tumor tissue occupied $>10 \%$ of the core area. Sections were then placed on microscope slides for further analysis.

Immunohistochemistry. Immunohistochemical staining was performed on the TMA slides, as described previously (30). Briefly, the TMA slides were heated to $60^{\circ} \mathrm{C}$ for $2 \mathrm{~h}$, de-waxed with xylene and rehydrated in graded ethanol sequentially $(100,95$ and $80 \%, v / v)$. Following antigen retrieval $[0.01 \mathrm{M}$ citrate buffer (Beijing Solarbio Science and Technology Co., Ltd., Beijing, China; $\mathrm{pH}, 6.0), 5 \mathrm{~min}$, pressure cooker] and endogenous peroxidase blockade $\left[3 \%(\mathrm{w} / \mathrm{v}) \mathrm{H}_{2} \mathrm{O}_{2}\right.$ in pure methanol], the slides were incubated with $10 \%$ normal goat serum (Beijing Solarbio Science \& Technology Co., Ltd.,) at room temperature for $10 \mathrm{~min}$ to reduce nonspecific reactions. Incubation with the primary antibody (rabbit monoclonal antibody to human Musashi-1; cat. no. 1877-1; dilution, 1:100; Epitomics) was performed in a moist chamber at $4^{\circ} \mathrm{C}$ overnight. Following washing three times with $0.01 \mathrm{M}$ phosphate buffer (Beijing Solarbio Science \& Technology Co., Ltd.; $\mathrm{pH}, 7.2$ ), the slides were incubated with secondary antibody (horseradish peroxidase-conjugated mouse monoclonal anti-rabbit immunoglobulin; cat. no. M0737; dilution, 1:1; Dako; Agilent Technologies Inc., Santa Clara, CA, USA) for $20 \mathrm{~min}$ at room temperature and stained with diaminobenzidine- $\mathrm{H}_{2} \mathrm{O}_{2}$. Finally, the TMA slides were counterstained with hematoxylin $(0.5 \%, \mathrm{w} / \mathrm{v})$, dehydrated and mounted on a coverslip using neutral balsam (Shanghai Specimen and Model Factory, Shanghai, China) and subsequently viewed under an optical microscope. Omission of primary antibody served as the negative control.
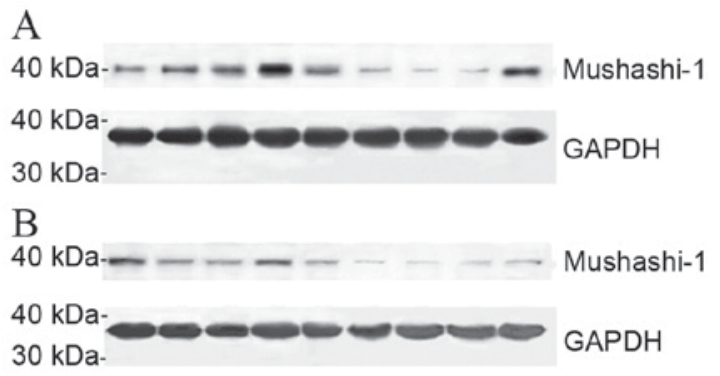

Figure 1. Representative western blots of Musashi-1 protein expression levels in cancerous and non-cancerous gastric tissues. (A) Gastric cancer tissues; (B) adjacent non-cancerous gastric mucosae. GAPDH, glyceraldehyde-3-phosphate dehydrogenase.

Evaluation of immunoreactivity. The Musashi-1 protein was immunohistochemically stained and independently examined under a light microscope by two pathologists who were blinded to the clinical data. The immunoreactivity was evaluated by applying a scoring system combining the intensity of immunostaining with the proportion of immunoreactive cells (30). In brief, the intensity of immunostaining was scored as 0 (no staining), 1 (weak staining, light yellow), 2 (moderate staining, yellow brown) and 3 (intense staining, brown), and the proportion of immunoreactive cells was scored as $0(\leq 5 \%$ positive cells), 1 (6-25\% positive cells), 2 (26-50\% positive cells) and 3 ( $\geq 51 \%$ positive cells). In the case of a discrepancy, a consensus score was selected. The product of the scores for intensity and proportion was used to signify the level of protein expression. The expression level of Musashi-1 was considered low if the product was $\leq 3$ and high if the product was $\geq 4$.

Statistical analysis. Quantitative data are presented as the mean \pm standard deviation. Data were analyzed using the Student's $t$-test, whereas categorical data were assessed using the $\chi^{2}$ test or Fisher's exact test. The correlation coefficients between protein expression and clinicopathological parameters were estimated using the Spearman correlation method. The Kaplan-Meier method was used to plot the survival curve and extract the cumulative survival rate and mean survival time. The difference between groups was compared with the log-rank test. Multivariate survival analysis was carried out using the Cox proportional hazards model, and variables that were significant in the univariate analysis were included in the model with the Enter method. All statistical analyses were performed using SPSS 16.0 for Windows (SPSS, Inc., Chicago, IL, USA). All P-values were two-sided, and $\mathrm{P}<0.05$ was considered to indicate a statistically significant difference.

\section{Results}

Expression levels of Musashi-1 protein in gastric cancer and non-cancerous gastric mucosae. The expression levels of Musashi-1 protein in 36 frozen gastric cancer tissues and the corresponding adjacent non-cancerous gastric mucosae were determined by western blotting. The relative expression levels of Musashi-1 protein in gastric cancer tissues were significantly higher compared with those in non-cancerous gastric mucosae $(0.317 \pm 0.045$ vs. $0.203 \pm 0.030 ; \mathrm{P}<0.05)$, there were no significant differences identified in Musashi-1 protein 

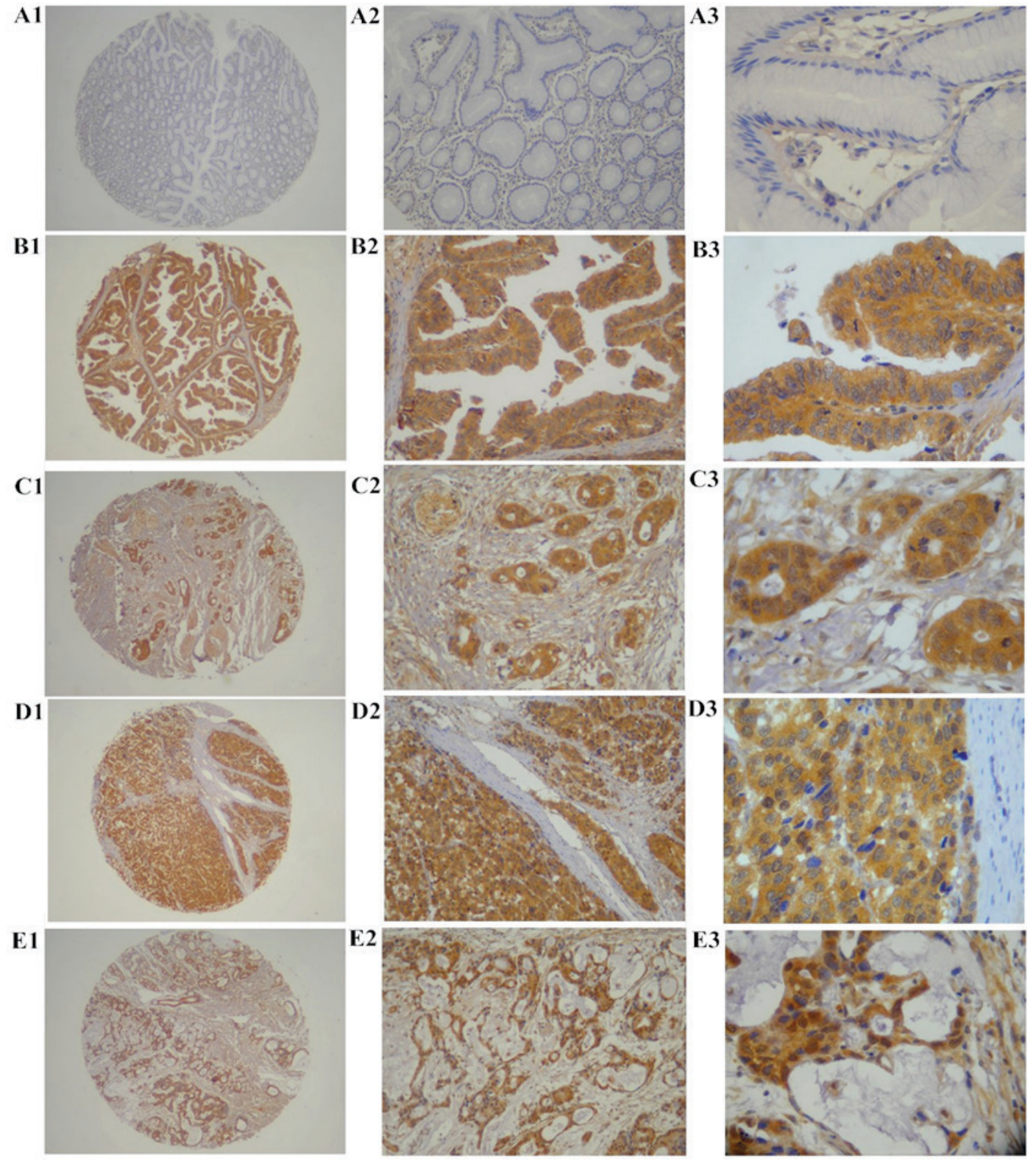

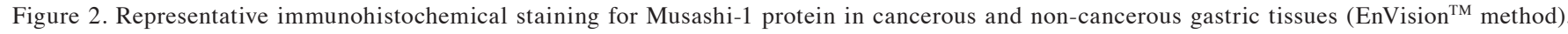
(A1-A3) No staining in adjacent non-cancerous gastric mucosa; (B1-B3) intense staining in papillary adenocarcinoma; (C1-C3) intense staining in tubular adenocarcinoma; (D1-D3) intense staining in poorly differentiated adenocarcinoma; (E1-E3) intense staining in mucinous adenocarcinoma. Magnification: (A1, B1, C1, D1 and E1) x40; (A2, B2, C2, D2 and E2) x100; (A3, B3, C3, D3 and E3) x400.

expression between intestinal-type and diffuse-type gastric cancer $(0.322 \pm 0.075$ vs. $0.312 \pm 0.051, \mathrm{P}>0.05)$, as presented in Fig. 1.

The expression of Musashi-1 protein in archived specimens of 436 gastric cancer tissues and 92 non-cancerous gastric mucosae was assessed by immunohistochemistry. Musashi-1 protein was predominantly expressed in the cytoplasm and on the membrane of epithelial cells (Fig. 2). Musashi-1 protein expression was detected in 215/436 (49.3\%) patients with gastric cancer, including high expression levels in 154 (35.3\%) cases, and low expression levels in 61 (14.0\%) patients, whereas Musashi-1 protein was weakly (12/92 cases) or not expressed in non-cancerous gastric mucosae tissues. The percentage of tissues with high Musashi-1 protein expression level was significantly higher $(\mathrm{P}<0.0001)$ in gastric cancer tissues compared with adjacent non-cancerous gastric mucosae tissues.
Correlation of Musashi-1 protein expression with clinicopathological parameters. The correlation was evaluated between Musashi-1 protein expression and clinicopathological parameters of patients with gastric cancer. The expression level of Musashi-1 protein in gastric cancer was associated with age, location, size, TNM stage, depth of invasion, vessel invasion, Lauren classification, lymph node metastasis and distant metastasis of the tumor, whereas it was not associated with gender, differentiation and the histological type of the tumor. Gastric cancer tissues from patients with with deep tumor invasion (T3 and T4), high TNM stage (stage III and IV), vessel invasion, lymph node metastasis and distant metastasis had significantly higher expression levels of Musashi-1 compared with those with superficial tumor invasion (T1 and T2), low TNM stage (stage I and II) and without vessel invasion or lymph node and distant metastasis (Table I). The 
Table I. Association of Musashi-1 protein expression with clinicopathological parameters of patients with gastric cancer.

\begin{tabular}{|c|c|c|c|c|c|c|}
\hline \multirow{2}{*}{$\begin{array}{l}\text { Clinicopathological } \\
\text { parameters }\end{array}$} & \multirow{2}{*}{$\begin{array}{l}\text { Total no. } \\
\text { patients }\end{array}$} & \multicolumn{2}{|c|}{$\begin{array}{c}\text { Musashi-1 } \\
\text { protein expression level }\end{array}$} & \multirow[b]{2}{*}{$\chi^{2}$} & \multirow[b]{2}{*}{ P-value } & \multirow[b]{2}{*}{$\mathrm{r}$} \\
\hline & & Low $(\mathrm{n}, \%)$ & High (n, \%) & & & \\
\hline Gender & & & & 0.168 & 0.682 & 0.020 \\
\hline Male & 311 & $203(65.3)$ & $108(34.7)$ & & & \\
\hline Female & 125 & $79(63.2)$ & $46(36.8)$ & & & \\
\hline Age range & & & & 7.607 & 0.006 & 0.132 \\
\hline$\leq 60$ years & 237 & $167(70.5)$ & $70(29.5)$ & & & \\
\hline$>60$ years & 199 & $115(57.8)$ & $84(42.2)$ & & & \\
\hline Location of tumor & & & & 11.332 & 0.003 & -0.137 \\
\hline Cardia & 55 & $25(45.5)$ & $30(54.5)$ & & & \\
\hline Body & 163 & $105(64.4)$ & $58(35.6)$ & & & \\
\hline Antrum & 218 & $152(69.7)$ & $66(30.3)$ & & & \\
\hline Tumor size & & & & 22.721 & $<0.0001$ & 0.228 \\
\hline$<5 \mathrm{~cm}$ & 256 & $189(73.8)$ & $67(26.2)$ & & & \\
\hline$\geq 5 \mathrm{~cm}$ & 180 & $93(51.7)$ & $87(48.3)$ & & & \\
\hline Depth of invasion & & & & 35.923 & $<0.0001$ & 0.287 \\
\hline $\mathrm{T} 1$ & 57 & $50(87.7)$ & $7(12.3)$ & & & \\
\hline $\mathrm{T} 2$ & 109 & 85 (78.0) & $24(22.0)$ & & & \\
\hline $\mathrm{T} 3$ & 244 & $136(55.7)$ & $108(44.3)$ & & & \\
\hline $\mathrm{T} 4$ & 26 & $11(42.3)$ & $15(57.7)$ & & & \\
\hline Vessel invasion & & & & 49.455 & $<0.0001$ & 0.337 \\
\hline Negative & 183 & $153(83.6)$ & $30(16.4)$ & & & \\
\hline Positive & 253 & $129(51.0)$ & $124(49.0)$ & & & \\
\hline TNM stage & & & & 96.863 & $<0.0001$ & 0.465 \\
\hline I & 90 & $83(92.2)$ & $7(7.8)$ & & & \\
\hline II & 104 & $86(82.7)$ & $18(17.3)$ & & & \\
\hline III & 173 & $95(54.9)$ & $78(45.1)$ & & & \\
\hline IV & 69 & $18(26.1)$ & $51(73.9)$ & & & \\
\hline Distant metastasis & & & & 38.402 & $<0.0001$ & 0.297 \\
\hline Negative & 375 & $264(70.4)$ & $111(29.6)$ & & & \\
\hline Positive & 61 & $18(29.5)$ & $43(70.5)$ & & & \\
\hline Lymph node metastasis & & & & 63.553 & $<0.0001$ & 0.382 \\
\hline Negative & 166 & $146(88.0)$ & $20(12.0)$ & & & \\
\hline Positive & 270 & $136(50.4)$ & $134(49.6)$ & & & \\
\hline Lauren classification & & & & 148.400 & $<0.0001$ & 0.583 \\
\hline Intestinal & 223 & $205(91.9)$ & $18(8.1)$ & & & \\
\hline Diffuse & 213 & $77(36.2)$ & $136(63.8)$ & & & \\
\hline Grade of differentiation & & & & 0.120 & 0.913 & 0.005 \\
\hline Well and moderate & 143 & $93(65.0)$ & $50(35.0)$ & & & \\
\hline Poor and not & 293 & $189(64.5)$ & $104(35.5)$ & & & \\
\hline Histological type & & & & 0.958 & 0.811 & 0.047 \\
\hline Papillary & 16 & $11(68.8)$ & $5(31.2)$ & & & \\
\hline Tubular & 326 & $214(65.6)$ & $112(34.4)$ & & & \\
\hline Mucinous & 29 & $18(62.1)$ & $11(37.9)$ & & & \\
\hline Signet-ring cell & 65 & $39(60.0)$ & $26(40.0)$ & & & \\
\hline
\end{tabular}

TNM, tumor-node-metastasis. 
Table II. Univariate analysis of the correlation between clinicopathological parameters and the survival rate of patients with gastric cancer.

\begin{tabular}{|c|c|c|c|c|c|c|}
\hline \multirow{2}{*}{$\begin{array}{l}\text { Clinicopathological } \\
\text { parameters }\end{array}$} & \multicolumn{3}{|c|}{ Cumulative survival (\%) } & \multirow{2}{*}{$\begin{array}{l}\text { Mean survival time } \\
\text { (months, } 95 \% \mathrm{CI} \text { ) }\end{array}$} & \multirow[b]{2}{*}{ Log-rank } & \multirow[b]{2}{*}{ P-value } \\
\hline & 1-year & 3-year & 5-year & & & \\
\hline Age range & & & & & 14.745 & $<0.001$ \\
\hline$\leq 60$ years & 95.4 & 69.6 & 40.6 & $45.8(43.7-48.0)$ & & \\
\hline$>60$ years & 88.4 & 57.3 & 23.1 & $39.6(37.0-42.2)$ & & \\
\hline Tumor location & & & & & 7.849 & 0.020 \\
\hline Cardia & 89.1 & 49.1 & 21.3 & $37.8(33.3-42.2)$ & & \\
\hline Body & 90.8 & 62.0 & 30.6 & $43.2(40.4-46.0)$ & & \\
\hline Antrum & 94.0 & 69.3 & 36.2 & $44.1(41.8-46.5)$ & & \\
\hline Tumor size & & & & & 49.579 & $<0.0001$ \\
\hline$<5 \mathrm{~cm}$ & 94.9 & 74.2 & 45.3 & $47.5(45.5-49.5)$ & & \\
\hline$\geq 5 \mathrm{~cm}$ & 88.3 & 49.4 & 15.1 & $36.6(33.9-39.3)$ & & \\
\hline Histological type & & & & & 0.934 & 0.817 \\
\hline Papillary & 93.8 & 62.5 & 23.4 & $41.9(34.7-49.1)$ & & \\
\hline Tubular & 93.3 & 63.8 & 33.7 & $43.3(41.3-45.2)$ & & \\
\hline Mucinous & 89.7 & 72.4 & 18.6 & $44.3(38.0-50.7)$ & & \\
\hline Signet-ring cell & 87.7 & 61.5 & 35.4 & $41.5(36.8-46.3)$ & & \\
\hline Grade of differentiation & & & & & 0.617 & 0.432 \\
\hline Well and moderate & 93.0 & 68.5 & 34.8 & $44.1(41.2-47.0)$ & & \\
\hline Poor and not & 91.8 & 61.8 & 31.2 & $42.4(40.4-44.5)$ & & \\
\hline TNM stage & & & & & 370.398 & $<0.0001$ \\
\hline I & 100.0 & 95.6 & 92.4 & $58.1(56.2-60.0)$ & & \\
\hline II & 96.2 & 83.7 & 72.5 & $53.0(50.1-55.8)$ & & \\
\hline III & 91.3 & 57.2 & 1.2 & $37.7(35.4-40.0)$ & & \\
\hline IV & 78.3 & 10.1 & 0.0 & $23.3(20.4-26.1)$ & & \\
\hline Depth of invasion & & & & & 135.118 & $<0.0001$ \\
\hline $\mathrm{T} 1$ & 100.0 & 93.0 & 90.9 & $57.2(54.7-59.7)$ & & \\
\hline $\mathrm{T} 2$ & 93.6 & 78.9 & 53.9 & $50.0(46.9-53.1)$ & & \\
\hline $\mathrm{T} 3$ & 90.6 & 55.3 & 14.6 & $38.4(36.2-40.5)$ & & \\
\hline $\mathrm{T} 4$ & 84.6 & 19.2 & 0.0 & $26.8(21.0-32.7)$ & & \\
\hline Lymph node metastasis & & & & & 176.051 & $<0.0001$ \\
\hline Negative & 97.6 & 86.1 & 78.4 & $54.2(52.1-56.4)$ & & \\
\hline Positive & 88.9 & 50.4 & 6.8 & $36.3(34.3-38.3)$ & & \\
\hline Distant metastasis & & & & & 141.372 & $<0.0001$ \\
\hline Negative & 95.2 & 72.3 & 37.5 & $46.2(44.6-47.9)$ & & \\
\hline Positive & 73.8 & 13.1 & 1.6 & $23.2(19.7-26.6)$ & & \\
\hline Vessel invasion & & & & & 127.410 & $<0.0001$ \\
\hline Negative & 97.8 & 86.3 & 67 & $52.6(50.5-54.6)$ & & \\
\hline Positive & 88.1 & 47.8 & 10.4 & $36.2(34.1-38.4)$ & & \\
\hline Lauren classification & & & & & 239.586 & $<0.0001$ \\
\hline Intestinal & 97.8 & 92.8 & 61.8 & $54.1(52.5-55.7)$ & & \\
\hline Diffuse & 86.4 & 33.8 & 4.4 & $31.5(29.4-33.7)$ & & \\
\hline Musashi-1 expression & & & & & 236.846 & $<0.0001$ \\
\hline Low & 97.2 & 86.9 & 48.9 & $51.1(49.5-52.8)$ & & \\
\hline High & 83.1 & 22.1 & 3.1 & $28.1(25.8-30.4)$ & & \\
\hline
\end{tabular}

CI, confidence interval; TNM, tumor-node-metastasis. 
Table III. Correlation between Musashi-1 protein expression level and mean survival time of 436 patients with gastric cancer as stratified by TNM stage.

Mean survival time (month, 95\% CI)

\begin{tabular}{lccrrr}
\cline { 2 - 3 } TNM stage & Musashi-1 low expression level & Musashi-1 high expression level & Log-rank & P-value \\
\hline I & $59.4(57.9-61.0)$ & $42.3(30.4-54.2)$ & 34.501 & $<0.0001$ \\
II & $56.8^{\mathrm{a}}(54.4-59.2)$ & $33.8(26.6-41.0)$ & 56.560 & $<0.0001$ \\
III & $44.0^{\mathrm{b}}(41.2-46.7)$ & $30.0(26.9-33.2)$ & 32.321 & $<0.0001$ \\
IV & $29.3(24.0-34.5)$ & $21.1(17.9-24.4)$ & 5.557 & 0.018 \\
\hline
\end{tabular}

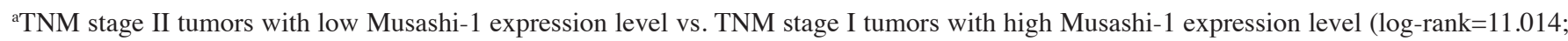
$\mathrm{P}=0.001)$. ${ }^{\mathrm{b}} \mathrm{TNM}$ stage III tumors with low Musashi-1 expression level vs. TNM stage II tumors with high Musashi-1 expression level (log-rank=4.503; $\mathrm{P}=0.034)$. $\mathrm{CI}$, confidence interval; TNM, tumor-node-metastasis.

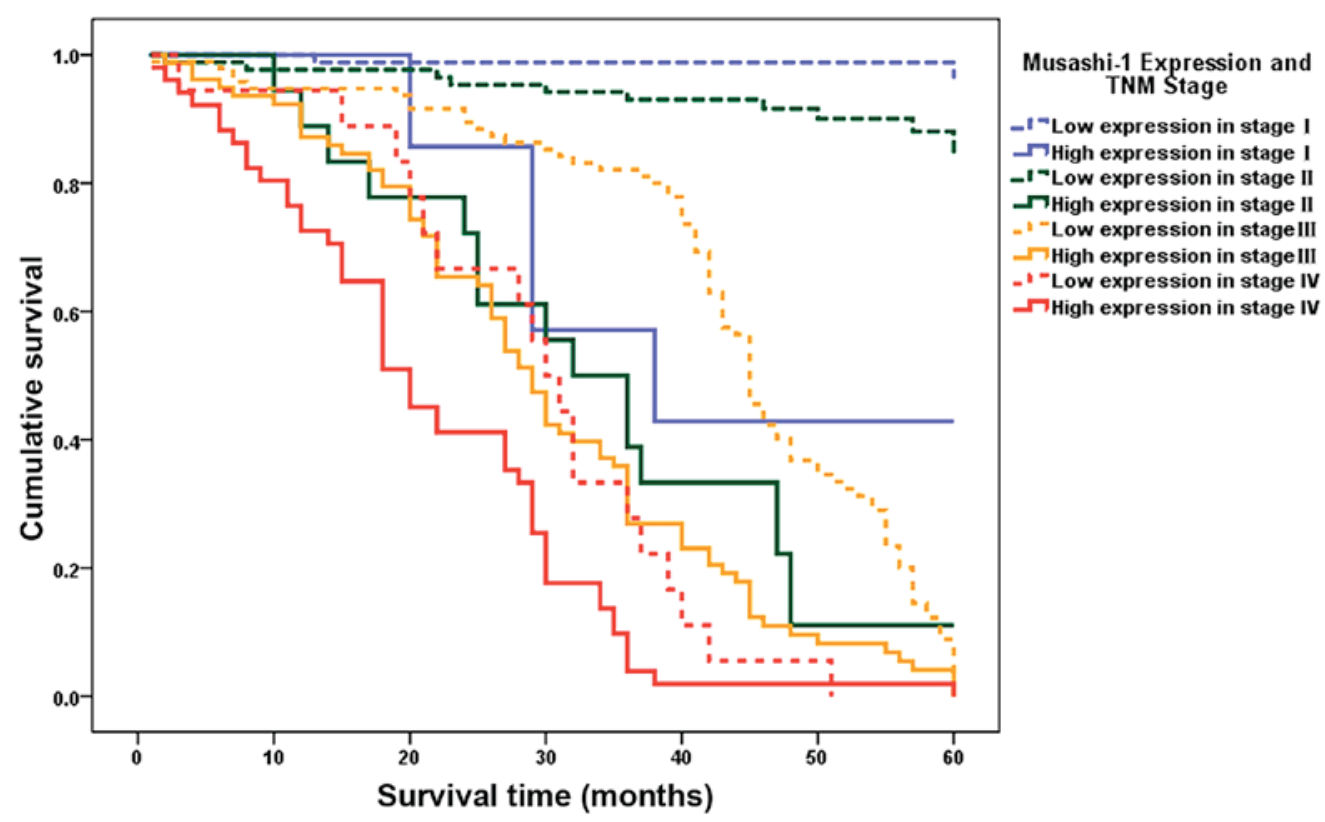

Figure 3. Kaplan-Meier survival curves of patients with gastric cancer with high and low levels of Musashi-1 protein expression as stratified by the tumor-node-metastasis stage of the tumor. TNM, tumor-node-metastasis.

Spearman's correlation coefficients of Musashi-1 expression level with depth of invasion, TNM stage, vessel invasion, lymph node metastasis and distant metastasis of tumor were $0.287,0.465,0.337,0.382$ and 0.297 , respectively.

Correlation between Musashi-1 protein expression level and prognosis of patients with gastric cancer. Univariate survival analysis indicated that high expression levels of Musashi-1 protein were associated with poor prognosis of patients with gastric cancer $(\log -r a n k=236.846 ; \mathrm{P}<0.0001)$. The 1-, 3- and 5-year cumulative survival rates were 97.2, 86.9 and $48.9 \%$, for patients with low Musashi-1 expression level, and 83.1,22.1 and $3.1 \%$ for patients with high Musashi-1 expression levels, respectively. The mean survival time for patients with low expression levels of Musashi-1 was 51.1 months, which was significantly higher $(\mathrm{P}<0.0001)$ compared with 28.1 months for patients with high expression levels of Musashi-1. It was also revealed that age, tumor location, size, depth of invasion, TNM stage, Lauren classification, vessel invasion, lymph node metastasis and distant metastasis were significantly associated with the survival of patients with gastric cancer, whereas histological type and grade of differentiation were not significantly associated with survival (Table II).

Upon stratification by TNM stage, the mean survival time of patients with low Musashi-1 expression level was significantly longer compared with that of patients with high Musashi-1 expression level in TNM stage I (59.4 vs. 42.3 months; $\mathrm{P}<0.0001)$, stage II (56.8 vs. 33.8 months; $\mathrm{P}<0.0001)$, stage III (44.0 vs. 30.0 months; $\mathrm{P}<0.0001$ ) and stage IV (29.3 vs. 21.1 months; $\mathrm{P}=0.018)$. Notably, patients with TNM II gastric cancer and low expression levels of Musashi-1 had a longer mean survival time compared with TNM stage I patients with high Musashi-1 expression levels (56.8 vs. 42.3 months; $\mathrm{P}<0.001$ ), and TNM stage III patients with low expression levels of Musashi-1 had a longer mean survival time compared with TNM stage II patients with high Musashi-1 expression levels (44.0 vs. 33.8 months, $\mathrm{P}=0.034$ ), as presented in Table III and Fig. 3. 
Table IV. Multivariate analysis of the correlation between clinicopathological parameters and the survival rate of 436 patients with gastric cancer.

\begin{tabular}{lcccc}
\hline Covariates & Coefficient & SE & HR (95\% CI) & P-value \\
\hline Age range ( $>60$ vs. $\leq 60)$ & 0.194 & 0.130 & $1.215(0.942-1.567)$ & 0.135 \\
Tumor location (cardia vs. other locations) & -0.168 & 0.180 & $0.846(0.595-1.202)$ & 0.350 \\
Tumor size $(\geq 5$ cm vs. $<5$ cm) & 0.061 & 0.131 & $1.062(0.822-1.373)$ & 0.644 \\
Lauren classification (diffuse vs. intestinal) & 0.673 & 0.170 & $1.960(1.404-2.737)$ & $<0.0001$ \\
Lymph node metastasis (positive vs. negative) & 0.203 & 0.335 & $1.225(0.635-2.365)$ & 0.545 \\
Vessel invasion (positive vs. negative) & -0.098 & 0.189 & $0.907(0.626-1.314)$ & 0.606 \\
Distant metastasis (positive vs. negative) & 0.707 & 0.272 & $2.028(1.189-3.458)$ & 0.009 \\
Musashi-1 protein expression (high vs. low) & 0.789 & 0.140 & $2.201(1.673-2.896)$ & $<0.0001$ \\
Depth of invasion & & & & 0.007 \\
T2 vs. T1 & 0.482 & 0.531 & $1.620(0.572-4.584)$ & 0.364 \\
T3 vs. T1 & 0.989 & 0.535 & $2.687(0.942-7.666)$ & 0.065 \\
T4 vs. T1 & 0.411 & 0.573 & $1.508(0.490-4.639)$ & 0.474 \\
TNM stage & & & & $<0.001$ \\
Stage II vs. stage I & 0.810 & 0.520 & $2.247(0.811-6.224)$ & 0.119 \\
Stage III vs. stage I & 2.088 & 0.604 & $8.069(2.472-26.341)$ & $<0.001$ \\
Stage IV vs. stage I & 2.594 & 0.654 & $13.380(3.715-48.187)$ & $<0.0001$ \\
\hline
\end{tabular}

CI, confidence interval; HR, hazard ratio; SE, standard error; TNM, tumor-node-metastasis.

Clinicopathological factors that were associated with the survival of patients with gastric cancer in the univariate survival analysis were included as covariates in the Cox regression analysis. It was revealed that Musashi-1 protein expression level, Lauren classification, distant metastasis, TNM stage and depth of invasion were independent prognostic indicators for the survival of patients with gastric cancer, whereas age, tumor location, size, lymph node metastasis and vessel invasion were not (Table IV).

\section{Discussion}

Musashi-1 expression has been identified to be restricted to the isthmus neck region (the putative position of stem cells) of normal gastric glands (26). Upregulation of Musashi-1 has previously been revealed to occur in rat gastric corpus mucosa, following ethanol-induced mucosal injury (31), leading to the suggestion that a subpopulation of parietal cells are a source of Musashi-1, which contributes to rapid re-epithelization by restoration of stem cells and regulation of cell differentiation (31). The Musashi-1 expression level has also been demonstrated to be associated with Helicobacter pylori infection (32). Increased expression levels of Musashi-1 in gastric precancerous lesions, including intestinal metaplasia and dysplasia, suggested that Musashi-1 may serve a crucial role in the carcinogenesis of gastric cancer (25).

In the present study, the results from western blotting and immunohistochemistry revealed that the expression levels of Musashi-1 protein in gastric cancer tissues were significantly higher compared with those in adjacent non-cancerous gastric mucosae. In discordance with a study by Choi et al (33), which demonstrated that Musashi-1 protein was more frequently overexpressed in young patients ( $\leq 30$ years) compared with in patients $>60$ years, the immunohistochemical assay of the present study demonstrated that Musashi-1 protein expression levels were significantly upregulated in patients aged $>60$ years compared with those aged $\leq 60$ years. There was a difference in age categorization between the current study and this previous study, and the cohort of the present study recruited only one patient aged $\leq 30$ years (17 years), making further analysis and comparison unattainable. The present study also indicated that the expression level of Musashi-1 in gastric cancer tissues was significantly associated with location, size, depth of invasion, vessel invasion, TNM stage, Lauren classification and lymph node and distant metastasis of the tumors. High Musashi-1 expression level was more frequently observed in tumors at high TNM stages (stages III and IV), with deep invasion (T3 and T4), presence of vessel invasion, lymph node metastasis and distant metastasis, compared with tumors at low TNM stages (stages I and II), with superficial invasion (T1 and T2), absence of vessel invasion, lymph node metastasis and distant metastasis. The results indicate that Musashi-1 may be involved in the invasion and metastasis of gastric cancer. Finally, it is of note that the immunohistochemistry assay demonstrated an association between high Musashi-1 protein expression levels and diffuse-type tumors, which was similar to the results of a previous study by Choi et al (33); however, the western blot analysis of the present study did not identify a difference in Musashi-1 expression level between diffuse-type and intestinal-type gastric cancer.

As a well-established stem/progenitor cell marker in both normal and cancer cells, Musashi-1 protein has been documented to be overexpressed in numerous types of cancer (34). The molecular mechanisms underlying the functions and regulation of Musashi-1 are not currently well known. Musashi-1 serves roles in the maintenance of the stem-cell 
state, differentiation and tumorigenesis as a translational repressor of target mRNAs (35). Musashi-1 protein upregulates the Notch signaling pathway by translationally suppressing Numb mRNA, a Notch pathway repressor (36). The Notch signaling pathway is established to control cell fate decisions and the stem cell phenotype (37), and is associated with the growth $(38,39)$ and progression $(40,41)$ of a wide spectrum of tumor types. Currently, the Musashi/Numb/Notch signaling pathway cascade is considered to be associated with numerous adult malignancies (42). The cyclin-dependent kinase inhibitor p21WAF-1 is another Musashi-1 target (43). It was revealed that Musashi-1 modulates endometrial carcinoma cell cycle progression and apoptosis via the stemness-associated factors Notch-1, Hes-1 and p21WAF-1 (44), thereby inducing crosstalk between a number of signal systems involved in the self-renewal of stem cells (10). Musashi-1 modulates cancer cell growth by the post-transcriptional regulation of phosphoinositide 3-kinase/protein kinase B signaling pathways (45). By contrast, within the context of a primary mammalian neural stem/progenitor cell, Musashi-1 may be converted from a repressor to an activator of mRNA translation in response to extracellular stimuli (11). Musashi-1 protein was also identified to serve an oncogenic role in hepatocellular carcinoma by activating the Wnt signaling pathway via direct downregulation of the tumor suppressor protein, Dickkopf-1 (46). In addition, tumor suppressor microRNAs (miRNAs) are known to target genes with oncogenic properties, including Musashi-1, and for being downregulated or deleted in tumor tissue (34). The long 3' untranslated region of Musashi-1 is potentially targeted by tumor suppressor miRNAs, thereby affecting its expression pattern during tumorigenesis of malignancies (34). miR-34a, $-101,-128,-137$ and -138 were revealed to function as tumor-suppressive miRNAs and negatively regulated Musashi-1 (47). Finally, Musashi-1 is also regulated by human antigen $\mathrm{R}$ via mRNA translation and stability in glioblastoma cells, which resulted in a positive regulation of Musashi-1 expression level (48).

As a result of its involvement in the invasion and metastasis of tumors, Musashi-1 had been proposed to be a biomarker associated with poor prognosis for a number of cancer subtypes (20-22). The present study demonstrated that the cumulative survival rates and mean survival time for patients with low Musashi-1 expression levels were significantly higher compared with those for patients with high Musashi-1 expression levels. Furthermore, it was revealed that a high expression level of Musashi-1 was an independent prognostic factor for patients with gastric cancer. Other factors correlated with the survival rate of patients included age, tumor location, size, depth of invasion, TNM stage, Lauren classification, vessel invasion, lymph node metastasis and distant metastasis. In addition, Lauren classification, distant metastasis, TNM stage and depth of invasion are independent prognostic indicators for the survival rate of patients with gastric cancer. As stratified by TNM stage, the mean survival time for patients with low Musashi-1 expression levels were significantly longer compared with that for patients with high Musashi-1 expression level in each TNM stage. Of note, patients with TNM stage II gastric cancer and low expression levels of Musashi-1 demonstrated a longer mean survival time compared with patients with TNM stage I and high Musashi-1 expression levels, and patients with TNM stage III gastric cancer and low expression levels of Musashi-1 revealed a longer mean survival time compared with patients with TNM stage II and high Musashi-1 expression levels. The results of the present study from univariate and multivariate survival analysis highlighted the prognostic relevance of Musashi-1 protein in patients with gastric cancer. Therefore, it was suggested that the expression level of Musashi-1 protein may be used on the basis of TNM stage to redefine the prognosis of patients with gastric cancer, contributing to developing a chemotherapeutic strategy for the effective treatment of gastric cancer.

In addition to being a putative prognostic factor for numerous malignancies, Musashi-1 has also received considerable attention as a potential target for cancer therapy $(16,49)$. Musashi-1-overexpressing cells exhibit tumorigenic properties in tumor graft experiments (50), whereas knockdown of Musashi-1 resulted in mitotic catastrophe, reduced cell proliferation and survival rate $(45,49)$, increased apoptosis in tumor cells and tumor growth arrest in grafts (51). A natural product (-)-gossypol was identified to inhibit colon cancer cell growth by targeting Musashi-1 protein (52). Further investigation revealed that Musashi-1 silencing significantly inhibited proliferative ability and attenuated the migration and invasion activity of colon cancer cells (16). The aforementioned observations suggested that the inhibition of Musashi-1's RNA binding activity may be an effective anticancer strategy and that Musashi-1 represents a promising target for anticancer agent discovery.

The limitation of the present study is the small size of tissue samples used in western blotting, which may partially account for the discordance in results regarding the association between Musashi-1 protein expression level and Lauren classification from immunohistochemistry and western blotting. Further studies are required to dissect the association between Musashi-1 protein expression level and Lauren classification for gastric cancer.

In conclusion, Musashi-1 protein serves an important role in the progression of gastric cancer. The detection of Musashi-1 protein expression level alone or in combination with TNM staging is useful for predicting the prognosis of patients with gastric cancer, therefore contributing to a personalized chemotherapy regimen. It is also possible that Musashi-1 may be used as a molecular target for gastric cancer treatment.

\section{Acknowledgements}

This study was supported by the Research Foundation of Science Technology Department of Zhejiang Province (grant no. 2008C33040) and the Medical Research Program of Zhejiang Province, China (grant nos. 2007A013 and 2013KYA018). The authors thank Ms. Wen-Juan Xu for assistance with specimen collection and follow-up.

\section{References}

1. Tore LA, Bray F, Siegel RL, Ferlay J, Lortet-Tieulent J and Jemal A: Global cancer statistics, 2012. CA Cancer J Clin 65: 87-108, 2015

2. Bertuccio P, Chatenoud L, Levi F, Praud D, Ferlay J, Negri E, Malvezzi M and La Vecchia C: Recent patterns in gastric cancer: A global overview. Int J Cancer 125: 666-673, 2009. 
3. Chen WQ, Zheng RS, Zhang SW, Zeng HM and Zou XN: The incidences and mortalities of major cancers in China, 2010. Chin J Cancer 33: 402-405, 2014.

4. Ferlay J, Soerjomataram I, Ervik M, Dikshit R, Eser S, Mathers C, Rebelo M, Parkin DM, Forman D and Bray F: GLOBOCAN 2012 v1.0, Cancer Incidence and Mortality Worldwide: IARC CancerBase No. 11 (Internet). International Agency for Research on Cancer, Lyon, France, 2013. http://globocan.iarc.fr. Accessed July 26, 2015.

5. Liu W, Yang Q, Liu B and Zhu Z: Serum proteomics for gastric cancer. Clin Chim Acta 431: 179-184, 2014.

6. Röcken C: Ways to personalized medicine for gastric cancer Pathologe 34: 403-412, 2013 (In German).

7. Humphries JM, Penno MA, Weiland F, Klingler-Hoffmann M, Zuber A, Boussioutas A, Ernst M and Hoffmann P: Identification and validation of novel candidate protein biomarkers for the detection of human gastric cancer. Biochim Biophys Acta 1844 1051-1058, 2014.

8. Wadhwa R, Song S, Lee JS, Yao Y, Wei Q and Ajani JA: Gastric cancer-molecular and clinical dimensions. Nat Rev Clin Oncol 10: 643-655, 2013

9. Yu Z, Pestell TG, Lisanti MP and Pestell RG: Cancer stem cells. Int J Biochem Cell Biol 44: 2144-2151, 2012.

10. Okano H, Kawahara H, Toriya M, Nakao K, Shibata S and Imai T: Function of RNA-binding protein Musashi-1 in stem cells. Exp Cell Res 306: 349-356, 2005.

11. MacNicol MC, Cragle CE and MacNicol AM: Context-dependent regulation of Musashi-mediated mRNA translation and cell cycle regulation. Cell Cycle 10: 39-44, 2011.

12. Siddall NA, McLaughlin EA, Marriner NL and Hime GR: The RNA-binding protein Musashi is required intrinsically to maintain stem cell identity. Proc Natl Acad Sci USA 103: 8402-8407, 2006

13. Song X, Zhou C, Zhou S, Zhang L, Feng G, Zhao D and Huang F: The expression patterns of Msil related with the glioma grade and the cytoplasmic Msi1 promotes angiogenesis. Tissue Cell 45 $1-6,2013$

14. Bobryshev YV, Freeman AK, Botelho NK, Tran D, LevertMignon AJ and Lord RV: Expression of the putative stem cell marker Musashi-1 in Barrett's esophagus and esophageal adenocarcinoma. Dis Esophagus 23: 580-589, 2010.

15. Fan LF, Dong WG, Jiang CQ, Xia D, Liao F and Yu QF: Expression of putative stem cell genes Musashi-1 and beta1-integrin in human colorectal adenomas and adenocarcinomas. Int J Colorectal Dis 25: 17-23, 2010.

16. Li D, Peng X, Yan D, Tang H, Huang F, Yang Y and Peng Z Msi-1 is a predictor of survival and a novel therapeutic target in colon cancer. Ann Surg Oncol 18: 2074-2083, 2011.

17. Liu DC, Yang ZL and Jiang S: Identification of musashi-1 and ALDH1 as carcinogenesis, progression, and poor-prognosis related biomarkers for gallbladder adenocarcinoma. Cancer Biomark 8: 113-121, 2010-2011.

18. Götte M, Wolf M, Staebler A, Buchweitz O, Kelsch R, Schüring AN and Kiesel L: Increased expression of the adult stem cell marker Musashi-1 in endometriosis and endometrial carcinoma. J Pathol 215: 317-329, 2008.

19. Wang Y, Jiang CQ and Fan LF: Correlation of Musashi-1, Lgr5, and pEGFR expressions in human small intestinal adenocarcinomas. Tumour Biol 36: 6075-6082, 2015.

20. Wang XY, Penalva LO, Yuan H, Linnoila RI, Lu J, Okano H and Glazer RI: Musashi1 regulates breast tumor cell proliferation and is a prognostic indicator of poor survival. Mol Cancer 9: 221, 2010.

21. Chen PX, Li QY and Yang Z: Musashi-1 expression is a prognostic factor in ovarian adenocarcinoma and correlates with ALDH-1 expression. Pathol Oncol Res 21: 1133-1140, 2015.

22. Ravindran $\mathrm{G}$ and Devaraj H: Prognostic significance of neural stem cell markers, Nestin and Musashi-1, in oral squamous cell carcinoma: Expression pattern of Nestin in the precancerous stages of oral squamous epithelium. Clin Oral Investig 19: $1251-1260,2015$

23. Kayahara T, Sawada M, Takaishi S, Fukui H, Seno H, Fukuzawa H, Suzuki K, Hiai H, Kageyama R, Okano H and Chiba T: Candidate markers for stem and early progenitor cells, Musashi-1 and Hes1, are expressed in crypt base columnar cells of mouse small intestine. FEBS Lett 535: 131-135, 2003.

24. Kuang RG, Kuang Y, Luo QF, Zhou CJ, Ji R and Wang JW: Expression and significance of Musashi-1 in gastric cancer and precancerous lesions. World J Gastroenterol 19: 6637-6644, 2013.
25. Wang T, Ong CW, Shi J, Srivastava S, Yan B, Cheng CL, Yong WP, Chan SL, Yeoh KG, Iacopetta B and Salto-Tellez M: Sequential expression of putative stem cell markers in gastric carcinogenesis. Br J Cancer 105: 658-665, 2011.

26. Akasaka Y, Saikawa Y, Fujita K, Kubota T, Ishikawa Y, Fujimoto A, Ishii $\mathrm{T}$, Okano $\mathrm{H}$ and Kitajima M: Expression of a candidate marker for progenitor cells, Musashi-1, in the proliferative regions of human antrum and its decreased expression in intestinal metaplasia. Histopathology 47: 348-356, 2005.

27. Lauren P: The two histological main types of gastric cancer: Diffuse and so-called intestinal type carcinoma. An attempt at a histo-clinical classification. Acta Pathol Microbiol Scand 64: 31-49, 1965

28. Bosman FT, Carneiro F, Hruban RH and Theise ND: WHO Classification of Tumours of the Digestive System. Vol 3. 4th edition. IARC Press, Lyon, 2010.

29. Sobin L, Gospodarowicz M and Wittekind C (eds): TNM Classification of Malignant Tumours. 7th edition. International Union Against Cancer, New York, NY, 2009.

30. Shou ZX, Jin $X$ and Zhao ZS: Upregulated expression of ADAM17 is a prognostic marker for patients with gastric cancer. Ann Surg 256: 1014-1022, 2012.

31. Nagata H, Akiba Y, Suzuki H, Okano H and Hibi T: Expression of Musashi-1 in the rat stomach and changes during mucosal injury and restitution. FEBS Lett 580: 27-33, 2006.

32. Murata H, Tsuji S, Tsujii M, Nakamura T, Fu HY, Eguchi H, Asahi K, Okano H, Kawano S and Hayashi N: Helicobacter pylori infection induces candidate stem cell marker Musashi-1 in the human gastric epithelium. Dig Dis Sci 53: 363-369, 2008.

33. Choi JE, Bae JS, Lee JH, Jang KY, Chung MJ and Moon WS Musashi-1 expression and clinicopathological significance in young gastric cancer patients: A matched case-control study. Int J Oncol 44: 1185-1192, 2014

34. Vo DT, Qiao M, Smith AD, Burns SC, Brenner AJ and Penalva LO: The oncogenic RNA-binding protein Musashil is regulated by tumor suppressor miRNAs. RNA Biol 8: 817-828, 2011.

35. Okano H, Imai T and Okabe M: Musashi: A translational regulator of cell fate. J Cell Sci 115: 1355-1359, 2002

36. Imai T, Tokunaga A, Yoshida T, Hashimoto M, Mikoshiba K, Weinmaster G, Nakafuku $M$ and Okano $H$ : The neural RNA-binding protein Musashil translationally regulates mammalian numb gene expression by interacting with its mRNA. Mol Cell Biol 21: 3888-3900, 2001.

37. Fender AW, Nutter JM, Bertrand FE and Sigounas G: Notch-1 promotes stemness and epithelial to mesenchymal transition in colorectal cancer. J Cell Biochem 116: 2517-2527, 2015.

38. Abravanel DL, Belka GK, Pan TC, Pant DK, Collins MA, Sterner CJ and Chodosh LA: Notch promotes recurrence of dormant tumor cells following HER2/neu-targeted therapy. J Clin Invest 125: 2484-2496, 2015.

39. Yen WC, Fischer MM, Axelrod F, Bond C, Cain J, Cancilla B, Henner WR, Meisner R, Sato A, Shah J, et al: Targeting notch signaling with a notch $2 /$ notch 3 antagonist (tarextumab) inhibits tumor growth and decreases tumor-initiating cell frequency. Clin Cancer Res 21: 2084-2095, 2015.

40. Yuan X, Wu H, Xu H, Han N, Chu Q, Yu S, Chen Y and Wu K: Meta-analysis reveals the correlation of Notch signaling with non-small cell lung cancer progression and prognosis. Sci Rep 5: $10338,2015$.

41. Chen W, Cao G, Yuan X, Zhang X, Zhang Q, Zhu Y, Dong Z and Zhang S: Notch-1 knockdown suppresses proliferation, migration and metastasis of salivary adenoid cystic carcinoma cells J Transl Med 13: 167, 2015.

42. Nishimoto $\mathrm{Y}$ and Okano $\mathrm{H}$ : New insight into cancer therapeutics: Induction of differentiation by regulating the Musashi/Numb/ Notch pathway. Cell Res 20: 1083-1085, 2010.

43. Battelli C, Nikopoulos GN, Mitchell JG and Verdi JM: The RNA-binding protein Musashi-1 regulates neural development through the translational repression of p21WAF-1. Mol Cell Neurosci 31: 85-96, 2006.

44. Götte M, Greve B, Kelsch R, Müller-Uthoff H, Weiss K, Kharabi Masouleh B, Sibrowski W, Kiesel L and Buchweitz O: The adult stem cell marker Musashi-1 modulates endometrial carcinoma cell cycle progression and apoptosis via Notch-1 and p21WAF1+CIP1. Int J Cancer 129: 2042-2049, 2011.

45. Muto J, Imai T, Ogawa D, Nishimoto Y, Okada Y, Mabuchi Y, Kawase T, Iwanami A, Mischel PS, Saya H, et al: RNA-binding protein Musashil modulates glioma cell growth through the post-transcriptional regulation of Notch and PI3 kinase/Akt signaling pathways. PLoS One 7: e33431, 2012. 
46. Chen K, Gao Q, Zhang W, Liu Z, Cai J, Liu Y, Xu J, Li J, Yang Y and $\mathrm{Xu} X$ : Musashi1 regulates survival of hepatoma cell lines by activation of Wnt signalling pathway. Liver Int 35: 986-998, 2015.

47. Smith AR, Marquez RT, Tsao WC, Pathak S, Roy A, Ping J, Wilkerson B, Lan L, Meng W, Neufeld KL, et al: Tumor suppressive microRNA-137 negatively regulates Musashi-1 and colorectal cancer progression. Oncotarget 6: 12558-12573, 2015.

48. Vo DT, Abdelmohsen K, Martindale JL, Qiao M, Tominaga K, Burton TL, Gelfond JA, Brenner AJ, Patel V, Trageser D, et al: The oncogenic RNA-binding protein Musashil is regulated by HuR via mRNA translation and stability in glioblastoma cells. Mol Cancer Res 10: 143-155, 2012.

49. Wang XY, Yu H, Linnoila RI, Li L, Li D, Mo B, Okano H, Penalva LO and Glazer RI: Musashil as a potential therapeutic target and diagnostic marker for lung cancer. Oncotarget 4 739-750, 2013.
50. Rezza A, Skah S, Roche C, Nadjar J, Samarut J and Plateroti M: The overexpression of the putative gut stem cell marker Musashi-1 induces tumorigenesis through Wnt and Notch activation. J Cell Sci 123: 3256-3265, 2010.

51. Sureban SM, May R, George RJ, Dieckgraefe BK, McLeod HL, Ramalingam S, Bishnupuri KS, Natarajan G, Anant S and Houchen CW: Knockdown of RNA binding protein musashi-1 leads to tumor regression in vivo. Gastroenterology 134: 1448-1458, 2008.

52. Lan L, Appelman C, Smith AR, Yu J, Larsen S, Marquez RT, Liu H, Wu X, Gao P, Roy A, et al: Natural product (-)-gossypol inhibits colon cancer cell growth by targeting RNA-binding protein Musashi-1. Mol Oncol 9: 1406-1420, 2015. 